\title{
Does GPER1 Play a Role in Sexual Dimorphism?
}

\author{
Janine L. Dovey and Nandini Vasudevan * \\ School of Biological Sciences, University of Reading, WhiteKnights Campus, Reading, United Kingdom
}

Estrogens are critical in driving sex-typical social behaviours that are ethologically relevant in mammals. This is due to both production of local estrogens and signaling by these ligands, particularly in an interconnected set of nuclei called the social behavioural network (SBN). The SBN is a sexually dimorphic network studied predominantly in rodents that is thought to underlie the display of social behaviour in mammals. Signalling by the predominant endogenous estrogen, $17 \beta$-estradiol, can be either via the classical genomic or non-classical rapid pathway. In the classical genomic pathway, 17 $\beta$ estradiol binds the intracellular estrogen receptors (ER) $\alpha$ and $\beta$ which act as liganddependent transcription factors to regulate transcription. In the non-genomic pathway,

OPEN ACCESS

Edited by:

Marilena Kampa,

University of Crete, Greece

Reviewed by:

Ernestina Marianna De Francesco,

University of Catania, Italy

Alain Couvineau,

Institut National de la Santé et de la Recherche Médicale (INSERM),

France

*Correspondence:

Nandini Vasudevan

n.vasudevan@reading.ac.uk

Specialty section:

This article was submitted to

Molecular and Structural

Endocrinology,

a section of the journal

Frontiers in Endocrinology

Received: 17 August 2020 Accepted: 08 October 2020

Published: 30 October 2020

Citation:

Dovey JL and Vasudevan N (2020) Does GPER1 Play a Role

in Sexual Dimorphism?

Front. Endocrinol. 11:595895. doi: 10.3389/fendo.2020.595895
$17 \beta$-estradiol binds a putative plasma membrane ER (mER) such as GPR30/GPER1 to rapidly signal via kinases or calcium flux. Though GPER1's role in sexual dimorphism has been explored to a greater extent in cardiovascular physiology, less is known about its role in the brain. In the last decade, activation of GPER1 has been shown to be important for lordosis and social cognition in females. In this review we will focus on several mechanisms that may contribute to sexually dimorphic behaviors including the colocalization of these estrogen receptors in the SBN, interplay between the signaling pathways activated by these different estrogen receptors, and the role of these receptors in development and the maintenance of the SBN, all of which remain underexplored.

\footnotetext{
Keywords: social behavior network, estrogen receptor isoforms, sex differences in brain, neuroestrogens, aromatase, mood, behavior
}

\section{INTRODUCTION}

The steroid hormone $17 \beta$-estradiol $\left(\mathrm{E}_{2}\right)$ is the most physiologically relevant estrogen, with a myriad of effects that is dependent on signaling from a receptor. The classical genomic mode of estrogen signaling is via nuclear estrogen receptors (ER) $\alpha$ and $\beta$, which translocate to the nucleus upon ligand binding to act as transcription factors, regulating transcription over hours to days (1). Nongenomic signaling is a second mode of estrogen signaling which employs membrane-limited forms of ER $\alpha$ and $\mathrm{ER} \beta$, as well as the novel G protein-coupled estrogen receptor (GPER)1, to activate second messenger pathways resulting in rapid outputs within seconds to minutes. In the brain, $\mathrm{E}_{2}$ acts via both signaling mechanisms to facilitate spinogenesis and dendrite growth $(2,3)$, cell survival (4), and neuroprotection (5). All these processes contribute to the sexual differentiation of the brain, a process that is restricted to critical periods of development in conserved nuclei of the brain referred to as the social behavior network [SBN; (6)]. After development, the $\mathrm{SBN}$ remains responsive to $\mathrm{E}_{2}$ acting via the ERs, 
integrating information about external and internal stimuli to drive sexually dimorphic expression of behaviors including reproductive behaviors, aggression and anxiety, and to some extent neuroprotection. In this review, we detail the contribution of the various ERs to the formation of the sexually dimorphic SBN and to the local production of estrogens, with areas of future exploration highlighted.

\section{THE SOCIAL BEHAVIOR NETWORK}

The social behavior network $(\mathrm{SBN})$ is a conserved set of hypothalamic and limbic nuclei that contribute to the expression of sex-typical social behaviors (6) via sexually dimorphic nuclei (SDN). These are structures within the SBN that differ in volume, cell type, and receptor expression between sexes. The neuroanatomical connections, and the contribution of each SBN nuclei to social behavior has been reviewed in detail in (7).

$E_{2}$ in the critical developmental period organizes the SBN (Figure 1) via molecular mechanisms that include neurogenesis $(10,11)$, programmed cell death (12), and synaptogenesis (13) and pruning (14). Following reproductive maturation, $\mathrm{E}_{2}$ then activates the SBN. Which ERs regulate these processes? In the female hippocampus, both ER $\alpha$ and GPER1 increase spinogenesis via ERK and JNK pathways (15) to consolidate spatial memories. Moreover, GPER1 activation leads to rapid increases in hippocampal spine density and promotes social cognition (16, 17). In neocortical cultures, GPER1 activation increases apoptosis mediated by the endocrine disrupter benzoquinone (18) while GPER1 activation can increase the migration of stem cells in the subventricular zone (19). Presumably, these processes are required for GPER1 modulation of sex-typical behaviors such as lordosis and social cognition. For details of the GPER1 including pharmacology, subcellular distribution and signaling, its role in behavior including its modulation of ER $\alpha$ function, the reader is directed to both $(9,20)$.

\section{Preoptic Area of the Hypothalamus}

The sexually dimorphic nucleus of the preoptic area (SDN-POA) has a larger volume in the male due to increased cell density (21). The perinatal androgen surge at E18 and subsequent aromatization to $\mathrm{E}_{2}$ protects dopaminergic cells in the male SDN-POA from apoptosis (22). The receptor for preserving the volume of the SDNPOA is ER $\alpha$, since WT and androgenized female rats treated with antisense oligonucleotides against $\mathrm{ER} \alpha$ show a significantly smaller SDN-POA volume compared to their respective controls (23) though ER $\alpha$ expression levels are not significant between the sexes (Table 1). Non-genomic signaling is critical since male mice with a mutation that destroys the tethering of the ER $\alpha$ to the membrane and its ability to initiate non-genomic signaling showed decreased calbindin-immunoreactive (a marker for the SDN-POA) neurones (37). Knockdown of Gper in zebrafish resulted in a greater number of cells stained with acridine orange, a marker for apoptosis (38). However, specific brain regions were not identified, and it is not known if this role for GPER1 exists in rodent species. Indeed, the localization of GPER1 within the SDN-POA has not been directly investigated, though efferents from the mPOA to the VTA do express GPER1 (39). Yet, despite its role in non-genomic signaling, the establishment of sexual dimorphisms by GPER1 in the POA is unknown.

\section{Anteroventral Periventricular Nucleus of the Hypothalamus}

The anteroventral periventricular nucleus (AVPV) contrasts from the neighboring SDN-POA as females harbor greater cell volumes (40), greater numbers of glia (41), and greater numbers of dopaminergic neurones (40) compared to males. The surge of $E_{2}$ availability in the perinatal male brain upregulates caspase activity and cell death whilst new cells are added to the female AVPV during puberty (11) though the ER that mediates this is not clear.

Adult females express greater amounts of $\mathrm{ER} \alpha$ than males (Table 1) and levels are not affected by gonadectomy (GDX) (32), which suggests that differences in expression occur prior to adulthood. ERKO $\alpha$ male mice have a greater AVPV volume (24) and a greater number of tyrosine hydroxylase $(\mathrm{TH})$-positive cells (42) than WT males. However, ER $\alpha \mathrm{KO}$ males still have significantly less dopaminergic neurones than WT females (42), suggesting that another receptor contributes to the masculinization of the AVPV. ER $\beta$ may be a candidate since it is coexpressed with both ER $\alpha$ and TH in the female AVPV (43) and ERKO $\beta$ males have increased $\mathrm{TH}$-ir compared to their WT counterparts (44). Together, this suggests that the sexual dimorphism in dopaminergic cell populations in the AVPV is driven by high levels of $E_{2}$ in the male brain acting through both $\mathrm{ER} \alpha$ and $\mathrm{ER} \beta$ to drive cell death. Interestingly, in cultured dopaminergic neurones shown to express both ER $\alpha$ and GPER1, $E_{2}$ is neuroprotective (5), suggesting that GPER1 may have a modulatory effect on ER $\alpha$ signaling. Though knockout of both $\alpha$ and $\beta$ ERs (ERKO) has no effect on glial cell numbers in the male AVPV (24), the death of glial cells is an $\mathrm{E}_{2}$-dependent process since aromatase $\mathrm{KO}$ (ArKO) mice have increased numbers of glial cells (24). This suggests that another ER, such as GPER1, that is abundant in glia, may contribute to the masculinization of the AVPV. Indeed, in an oxygen-glucose deprivation model, GPER1 increases apoptosis of cortical astrocytes (45). Neither expression of the GPER1 protein, nor its colocalization with other ERs in the AVPV, have been characterized in the male or female rodent.

\section{The Medial and Extended Amygdala}

The medial amygdala (MeA) is a major source of input to the medial (m)POA, responsible for relaying olfactory information that underlies social recognition. Similar to the AVPV, new cells are added to the MeA during puberty albeit solely in the male (11). Targeted knockdown of ER $\alpha$ in the MeA in pubertal male mice feminizes the volume of the $\mathrm{MeA}$ by reducing neuron numbers (46), suggesting ER $\alpha$-mediated signaling is important in the establishment of volumetric sex differences.

Aromatase is strongly expressed in the MeA of male mice, particularly in nerve fibers (34) and may contribute to the modulation of synaptic properties of the female MeA across the estrous cycle (47), as $\mathrm{E}_{2}$ inhibits neural transmission from the MeA (48). Indeed, administration of the GPER1 agonist G-1 


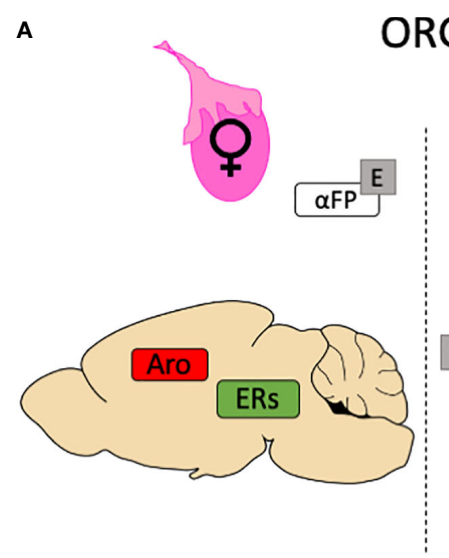

ORGANISATION
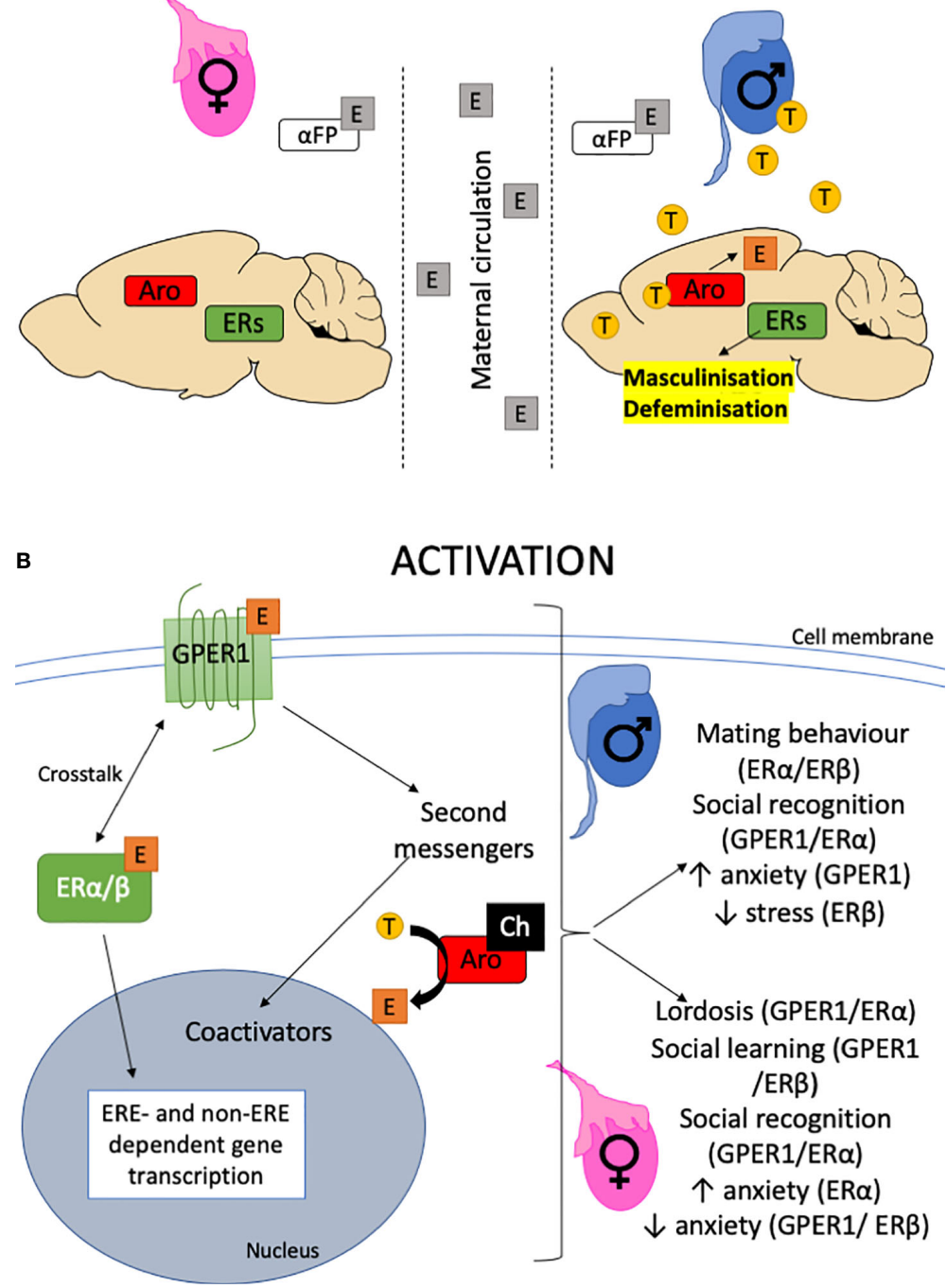

FIGURE 1 | Organizational-activational hypothesis. (A) The testes are active during perinatal development providing testosterone for central aromatase (Aro) to produce estrogen (E) within the brain. Estrogen organizes the brain by binding to ERs, leading to the masculinization and defeminization of the brain. By contrast, the perinatal ovary is quiescent. In utero, the brain is protected from estrogens that may enter via maternal circulation by the presence of $\alpha$-fetoprotein that binds estrogen. The role of the GPER1 in this organizational period is largely unknown. For a detailed review, the reader is referred to (8) and references therein. (B) The organized neural substrate is activated following puberty when the gonads become active. Estrogen is released from the ovaries and testosterone (T) from the testes, which is then aromatized to estrogen in the brain. The availability of cholesterol (Ch) and presence of steroidogenic enzymes within the brain also allows for the de novo production of neuroestrogens. Estrogens activate neural circuits to express behaviors through activating second messenger pathways such as MAPK acutely and recruiting transcriptional coactivators such as fos and jun to regulate non-ERE containing promoters. This could be via multiple ERs, including GPER1 (9). Alternatively, the classical nuclear hormone receptors, ER $\alpha / \beta$ can translocate to the nucleus to directly bind estrogen-response-elements in DNA to regulate gene transcription. Both these pathways result in modulation of behaviors in both males and females.

attenuates the upregulation of NMDA receptors in the female basolateral amygdala and blocks the downregulation of $\mathrm{GABA}_{\mathrm{A}}$ receptors to increase inhibitory synaptic transmission (49).

The bed nucleus of the stria terminalis (BNST) is part of the extended amygdala and plays a key role in stress and anxietydenoting behaviors (50), expressing both ER $\alpha$ and ER $\beta$ during developmental periods (Table 1). A subregion of the BNST, the principal nucleus of the BNST (BNSTp) is larger in males than females (51). Administration of testosterone propionate (TP) to females at P1 increases volume, although not to a level comparable with males (52-54). This may be a reflection of greater aromatase expression within the male BNST (34), allowing the brain to generate more estrogen to produce a greater magnitude of masculinization. In addition, it could be a reflection of less androgen receptor (AR) expression in the female brain (55), since masculinization of the BNSTp requires both $\mathrm{E}_{2}$ signaling and 
TABLE 1 | Sexual dimorphisms in central ER and aromatase expression across development.

\begin{tabular}{|c|c|c|c|c|c|c|c|c|c|c|c|c|}
\hline \multirow[t]{2}{*}{ Area } & \multicolumn{3}{|c|}{$\mathrm{ER} \alpha$} & \multicolumn{3}{|c|}{ ER $\beta$} & \multicolumn{3}{|c|}{ GPER1 } & \multicolumn{3}{|c|}{ Aromatase } \\
\hline & Pn & $\mathrm{Pb}$ & A & Pn & $\mathrm{Pb}$ & A & Pn & $\mathrm{Pb}$ & A & Pn & $\mathrm{Pb}$ & A \\
\hline \multicolumn{13}{|l|}{ Hypothalamus } \\
\hline $\mathrm{ARH}$ & $={ }^{7,8}$ & $={ }^{7}$ & & $x^{3}$ & $={ }^{3}$ & & & & $={ }^{13}$ & & & $={ }^{11}$ \\
\hline $\mathrm{VMH}$ & $=7,8$ & $\mathrm{~F}^{7}$ & & $F^{6}$ & $={ }^{6}$ & $={ }^{\star} 12$ & & & $=13$ & $={ }^{\star} 4$ & & \\
\hline $\mathrm{PVH}$ & & $={ }^{7}$ & & & & $=^{\star 12}$ & & & & & & $={ }^{11}$ \\
\hline LS & $={ }^{7}$ & $={ }^{7}$ & & & & & & & $={ }^{13}$ & & & \\
\hline AVPV & $F^{1,9}$ & & $\mathrm{~F}^{9}$ & $x^{1}$ & $x^{10}$ & & & & $={ }^{13}$ & & & \\
\hline $\mathrm{mPOA}$ & $=7,8$ & $F^{7,8}$ & & $={ }^{3}$ & $\mathrm{~F}^{3}$ & $M^{\star 12}$ & & & $={ }^{13}$ & $x^{* 4}$ & & $M^{2,11}$ \\
\hline \multicolumn{13}{|c|}{ Extended amygdala } \\
\hline BNST & $F^{1,9}$ & $={ }^{7,9}$ & $\mathrm{~F}^{9}$ & $=1$ & & $M^{* 12}$ & & & $={ }^{13}$ & $={ }^{1} M^{* 4}$ & & $M^{2}$ \\
\hline $\mathrm{MeA}$ & & $={ }^{7}$ & & & & $F^{\star 12}$ & & & $={ }^{13}$ & $={ }^{\star 4}$ & & $M^{2}$ \\
\hline Bird song areas & & & & & & & & $M^{5}$ & $M^{5}$ & & & \\
\hline
\end{tabular}

Relative expression of receptors and aromatase during perinatal (Pn), pubertal (Pb), and adult ( $A$ ) periods. "F" denotes a greater expression in females, " $M$ " a greater expression in males, "=" an equal expression between males and females, and " $X$ " indicates undetectable expression. All referenced research uses mouse or rat (") models, apart from one study which used zebra finches to study GPER1 expression in song areas. References 1-5 measured mRNA expression; references 7-12 measured protein expression; reference 6 measured both mRNA and protein. 1. (24). 2. (25). 3. (26). 4. (27). 5. (28). 6. (29). 7. (30). 8. (31). 9. (32). 10. (33). 11. (34). 12. (35). 13. (36).

testosterone signaling via the AR (24). Similar to the AVPV, both $E R \alpha$ and $\operatorname{ER} \beta$ are required for complete masculinization of the BNSTp, since PPT and DPN (ER $\alpha$ and ER $\beta$ agonists respectively) given in the perinatal period increase cell number of the female BNSTp, but neither completely mimicked the effects of $E_{2}$ alone (56), suggesting that synergy between ERs, including GPER1 may maintain sexual dimorphism.

The pattern of expression of the ERs (Table 1) and the use of pharmacological and genetic studies to target them suggest that the development of the SBN frequently depends on a combination of $\mathrm{ER} \alpha$ and GPER1 though it often appears that the role of ER $\alpha$ is predominant. This suggests that both membrane-initiated signaling and classical transcriptional signaling might be important for sextypical behaviors that are responsive to external stimuli over longer time frames. The idea that GPER1 may facilitate or antagonize ER $\alpha$ signaling has been reviewed in (20) with examples given within and outside the brain. Given that the male brain expresses more aromatase and has more neuroestrogens (Section 3), we speculate that in most instances, neuromorphological organizational changes are driven by these ERs in the male, rather than the female brain.

A number of caveats exist to the localization data. First, most studies have compared the longitudinal dynamics of ER expression in the SBN of wildtype (WT) animals, focusing largely on sexual dimorphisms within one particular age window and/or nucleus. Unusually, a recent study showed that ER $\alpha$ and GPER1 were higher in the striatum of both male and female rats during development and perinatal life but then declined in a sexually dimorphic manner as development proceeded (57); however, they did not explore such developmental dynamics in the SBN. Secondly, due to antibody issues, colocalization studies of GPER1 with the other ERs have not been performed.

\section{LOCAL ESTROGEN SYNTHESIS WITHIN THE SBN}

Apart from the contribution of the ERs, another mechanism that affects SBN nuclei is the provision of local estrogens. The brain expresses the enzymes required to synthesize estrogens de novo (neuroestrogens) $(58,59)$. Developmentally, central aromatase may be important for allowing specific regions to access higher concentrations of $\mathrm{E}_{2}$ to maintain cell numbers or drive apoptosis, although more evidence is required to support this idea. In an activational context, aromatase may be important for maintaining stable concentrations of neuroestrogens when systemic concentrations fluctuate across the estrous cycle, as seen in female baboons (60).

\section{Regulation of Aromatase: Substrate Availability and Development}

Is the regulation of aromatase sexually dimorphic? In limbic areas, aromatase activity appears to be constitutive (61). Therefore, the regulation of aromatase activity is proposed to rely on two different systems: a gonad-sensitive hypothalamic system and a non-gonadsensitive limbic system $(62,63)$. Though there are no sex differences in aromatase mRNA expression in the BNST or AVPV during perinatal development (24), male rodents have greater levels of aromatase gene expression than females by adulthood (25). In line with this, prepubertal GDX in males reduces aromatase activity in adulthood (64), suggesting that aromatase expression is pubertally organized by pubertal gonadal hormones.

The regulation of central aromatase may also be determined by estrogens themselves. In MCF-7 cells, aromatase activity is upregulated by estrogens in a positive autocrine feedback loop via either $\mathrm{ER} \alpha$ or $\operatorname{GPER} 1(65,66)$. In transgenic mice that express EGFP in aromatase-positive neurons, EGFP is more highly co-expressed with $\mathrm{ER} \alpha, \mathrm{ER} \beta$ and $\mathrm{AR}$ in the male BNST and $\mathrm{MeA}$ than in the adult female though co-expression of the ERs and AR with EGFP was prevalent in other nuclei of the SBN of both sexes (34). In contrast, aromatase is mostly co-expressed with ER $\alpha$ during the perinatal period (67), highlighting the potential to investigate developmental change in co-expression, which may be partly explained by the sexually dimorphic addition of new cells during puberty (11). How GPER1 regulates aromatase in the $\mathrm{SBN}$ is a question that is currently being investigated by us. 


\section{DISCUSSION: THERAPEUTIC POTENTIAL FOR GPER1}

Why is the contribution of GPER1 to a sexually dimorphic SBN important? A sexually dimorphic brain results in sexually dimorphic disorders that are important to consider clinically. For example, neurodegenerative diseases disproportionately affect women (68), whereas learning difficulties such as those associated with autism spectrum disorder and dyslexia are more commonly observed in males (69). Females have a greater risk of developing depression, anxiety, or panic disorders (70) which are correlated with hormonal changes in puberty and menopause (71). $\mathrm{E}_{2}$ can elicit anxiogenic or anxiolytic effects in the amygdala (72). ER $\alpha$ knockdown in the medial posterodorsal amygdala (MePDA) resulted in female rats spending more time in the light chamber in the light-dark test (LDT), implicating ER $\alpha$ as anxiogenic (73). On the other hand, there is a general consensus that ER $\beta$ is anxiolytic (72) while the role of GPER1 is less clear. Chronic administration of G-1 was anxiolytic in the open field test (OFT), but not the elevated plus maze (EPM) (74) in females while acute administration of G1 was anxiolytic in the EPM within 30 min of administration in males but not females (75). On the contrary, another study found that agonism of GPER1 produced anxiogenic effects in both the OFT and EPM (76) in male and female mice. In this study, G-1 was injected $2 \mathrm{~h}$ before behavioral testing. Thus, the timeframe of administration may be an important factor in determining the roles of ERs in anxiety. The actions of GPER1 may also depend on the context of anxiety, i.e. whether the animal is previously stressed. Acute stress (imposed by restraint or forced swim tests) significantly decreased the time spent in the open arms and central area of the EPM, but this is ameliorated with G-1 treatment (49) in ovariectomized females. Moreover, acute stress significantly increased the levels of GluR1-containing AMPA receptors and NR2A-containing NMDA receptors, thus increasing small excitatory postsynaptic currents (sEPSCs). However, G-1 treatment reversed these effects, enhancing small inhibitory postsynaptic currents (sIPSCs) instead (49). Thus, GPER1 may be important in mitigating stress-induced anxiety, with little-tono role in inhibiting behaviors that denote anxiety in the absence of stress. This specificity might allow for the development of personalized medications for anxiety. Furthermore, targeting GPER1 over ER $\alpha$ or ER $\beta$ may be preferable given the possible sexual dimorphism in anxiety modulation (75), involvement of the classical ERs in reproductive development and function, and the role of ER $\beta$ the in estrogenic modulation of $\mathrm{GnRH}$ (77)

\section{FUTURE PERSPECTIVES}

Clearly, understanding how GPER1 functions both independently and as a putative modulator of classical ERs in both sexes is imperative for uncovering its therapeutic potential in hormone-associated mood disorders. GPCRs such as the serotonin $1 \mathrm{~A}$ receptor have been associated with the development of depression. SSRIs function by desensitizing serotonin $1 \mathrm{~A}$ receptor signaling to decrease plasma levels of oxytocin and adrenocorticotropic hormone (ACTH) (78). The efficacy of SSRIs in attenuating serotonin 1A receptor mediated signaling and consequent oxytocin and ACTH release can be accelerated with G-1 treatment. Dual treatment targeting GPER1 means that symptoms of depression can be alleviated earlier, as it takes up to 12 weeks to reach clinical efficacy with SSRIs alone (79). Furthermore, a recent study has implicated GPER1 as a diagnostic tool for GAD and MDD. Drug-naïve patients with anxiety or depressive disorders exhibit increased serum levels of GPER1, which correlate with anxiety scores (80). This result was found to be independent of sex although mouse models suggest that the role of GPER1 in regulating anxiety is slightly more pronounced in males $(76,81)$. Though there is a general lack of sexual dimorphism in GPER1 expression with moderate to high distribution of GPER1 in the adult SBN (36), a recent study has shown that GPER1 concentrations decrease with approaching adulthood and the distribution shifts from multicompartment to predominantly cytoplasmic or membrane distribution in the striatum (57). This suggests that GPER1 expression is capable of being developmentally regulated though the significance of such regulation remains unknown. Moreover, the effects of GPER1 activation in adulthood on molecular mechanisms linked to sexual dimorphism raise the possibility that GPER1 may have similar effects in the perinatal and pubertal critical periods. This could be investigated by determining a) the expression of GPER1 in development versus adulthood in the SBN and its colocalization with ER $\alpha, E R \beta$; and aromatase; b) the effect of GPER1 agonism with G-1 and antagonism with specific antagonist G-15 and G-36 during the critical periods on sex differences in morphology, neuroestrogen production, and molecular signaling prevalent in the SBN; c) the nature of modulation of ER $\alpha$ action in the SBN. Some of this may be explored with the use of a conditional, regional GPER1KO model, though this is yet to be generated. Therefore, the distinct roles of GPER1 within specific limbic vs SBN nuclei in adulthood versus developmental periods need to be better understood to produce a targeted medication to alter mood without changing the expression of sex-typical organized behaviors involving GPER1, such as reproduction.

\section{AUTHOR CONTRIBUTIONS}

Both JD and NV wrote and modified the text of the article after discussions. JD was responsible for the figure and the Table 1 (which was further modified by NV). All authors contributed to the article and approved the submitted version.

\section{FUNDING}

JD is supported by the School of Biological Sciences, University of Reading. 


\section{REFERENCES}

1. Hall JM, Couse JF, Korach KS. The multifaceted mechanisms of estradiol and estrogen receptor signaling. J Biol Chem (2001) 276(40):36869-72. doi: 10.1074/jbc.R100029200

2. Kretz O, Fester L, Wehrenberg U, Zhou L, Brauckmann S, Zhao S, et al. Hippocampal synapses depend on hippocampal estrogen synthesis. J Neurosci (2004) 24(26):5913-21. doi: 10.1523/JNEUROSCI.5186-03.2004

3. Mukai H, Tsurugizawa T, Murakami G, Kominami S, Ishii H, Ogiue-Ikeda M, et al. Rapid modulation of long-term depression and spinogenesis via synaptic estrogen receptors in hippocampal principal neurons. J Neurochem (2007) 100(4):950-67. doi: 10.1111/j.1471-4159.2006.04264.x

4. Hill RA, Pompolo S, Jones ME, Simpson ER, Boon WC. Estrogen deficiency leads to apoptosis in dopaminergic neurons in the medial preoptic area and arcuate nucleus of male mice. Mol Cell Neurosci (2004) 27(4):466-76. doi: 10.1016/j.mcn.2004.04.012

5. Bourque M, Morissette M, Di Paolo T. Neuroprotection in Parkinsoniantreated mice via estrogen receptor alpha activation requires $G$ proteincoupled estrogen receptor 1. Neuropharmacology (2015) 95:343-52. doi: 10.1016/j.neuropharm.2015.04.006

6. Newman SW. The medial extended amygdala in male reproductive behavior. A node in the mammalian social behavior network. Ann N Y Acad Sci (1999) 877:242-57. doi: 10.1111/j.1749-6632.1999.tb09271.x

7. Greenberg GD, Trainor BC. Sex Differences in the Social Behavior Network and Mesolimbic Dopamine System. Sex differences in the central nervous system. San Diego: Academic Press (2016) p. 77-106.

8. Ogawa S, Tsukahara S, Choleris E, Vasudevan N. Estrogenic regulation of social behavior and sexually dimorphic brain formation. Neurosci Biobehav Rev (2020) 110:46-59. doi: 10.1016/j.neubiorev.2018.10.012

9. Vajaria R, Vasudevan N. Is the membrane estrogen receptor, GPER1, a promiscuous receptor that modulates nuclear estrogen receptor-mediated functions in the brain? Horm Behav (2018) 104:165-72. doi: 10.1016/ j.yhbeh.2018.06.012

10. He J, Crews FT. Neurogenesis decreases during brain maturation from adolescence to adulthood. Pharmacol Biochem Behav (2007) 86(2):327-33. doi: 10.1016/j.pbb.2006.11.003

11. Ahmed EI, Zehr JL, Schulz KM, Lorenz BH, DonCarlos LL, Sisk CL. Pubertal hormones modulate the addition of new cells to sexually dimorphic brain regions. Nat Neurosci (2008) 11(9):995-7. doi: 10.1038/nn.2178

12. Nunez JL, Sodhi J, Juraska JM. Ovarian hormones after postnatal day 20 reduce neuron number in the rat primary visual cortex. J Neurobiol (2002) 52 (4):312-21. doi: 10.1002/neu.10092

13. Huttenlocher PR, Dabholkar AS. Regional differences in synaptogenesis in human cerebral cortex. J Comp Neurol (1997) 387(2):167-78. doi: 10.1002/ (sici)1096-9861(19971020)387:2<167::aid-cne1>3.0.co;2-Z

14. Zehr JL, Todd BJ, Schulz KM, McCarthy MM, Sisk CL. Dendritic pruning of the medial amygdala during pubertal development of the male Syrian hamster. J Neurobiol (2006) 66(6):578-90. doi: 10.1002/neu.20251

15. Kim J, Szinte JS, Boulware MI, Frick KM. 17beta-Estradiol and Agonism of Gprotein-Coupled Estrogen Receptor Enhance Hippocampal Memory via Different Cell-Signaling Mechanisms. J Neurosci (2016) 36(11):3309-21. doi: 10.1523/JNEUROSCI.0257-15.2016

16. Ervin KS, Mulvale E, Gallagher N, Roussel V, Choleris E. Activation of the G protein-coupled estrogen receptor, but not estrogen receptor alpha or beta, rapidly enhances social learning. Psychoneuroendocrinology (2015) 58:51-66. doi: 10.1016/j.psyneuen.2015.04.002

17. Gabor C, Lymer J, Phan A, Choleris E. Rapid effects of the G-protein coupled oestrogen receptor (GPER) on learning and dorsal hippocampus dendritic spines in female mice. Physiol Behav (2015) 149:53-60. doi: 10.1016/ j.physbeh.2015.05.017

18. Wnuk A, Rzemieniec J, Lason W, Krzeptowski W, Kajta M. Apoptosis Induced by the UV Filter Benzophenone-3 in Mouse Neuronal Cells Is Mediated via Attenuation of Eralpha/Ppargamma and Stimulation of Erbeta/Gpr30 Signaling. Mol Neurobiol (2018) 55(3):2362-83. doi: 10.1007/ s12035-017-0480-Z

19. Haumann I, Sturm MA, Anstotz M, Rune GM. GPER1 Signaling Initiates Migration of Female V-SVZ-Derived Cells. iScience (2020) 23(5):101077. doi: $10.1016 /$ j.isci.2020.101077
20. Hadjimarkou MM, Vasudevan N. GPER1/GPR30 in the brain: Crosstalk with classical estrogen receptors and implications for behavior. J Steroid Biochem Mol Biol (2018) 176:57-64. doi: 10.1016/j.jsbmb.2017.04.012

21. Gorski RA, Harlan RE, Jacobson CD, Shryne JE, Southam AM. Evidence for the existence of a sexually dimorphic nucleus in the preoptic area of the rat. J Comp Neurol (1980) 193(2):529-39. doi: 10.1002/cne.901930214

22. Davis EC, Popper P, Gorski RA. The role of apoptosis in sexual differentiation of the rat sexually dimorphic nucleus of the preoptic area. Brain Res (1996) 734(1-2):10-8. doi: 10.1016/0006-8993(96)00298-3

23. McCarthy MM, Schlenker EH, Pfaff DW. Enduring consequences of neonatal treatment with antisense oligodeoxynucleotides to estrogen receptor messenger ribonucleic acid on sexual differentiation of rat brain. Endocrinology (1993) 133(2):433-9. doi: 10.1210/endo.133.2.8344188

24. Kanaya M, Tsuda MC, Sagoshi S, Nagata K, Morimoto C, Thu CK, et al. Regional difference in sex steroid action on formation of morphological sex differences in the anteroventral periventricular nucleus and principal nucleus of the bed nucleus of the stria terminalis. PloS One (2014) 9(11):e112616. doi: 10.1371/journal.pone.0112616

25. Tabatadze N, Sato SM, Woolley CS. Quantitative analysis of long-form aromatase mRNA in the male and female rat brain. PloS One (2014) 9(7): e100628. doi: 10.1371/journal.pone.0100628

26. Cao J, Patisaul HB. Sexually dimorphic expression of hypothalamic estrogen receptors alpha and beta and Kiss1 in neonatal male and female rats. J Comp Neurol (2011) 519(15):2954-77. doi: 10.1002/cne.22648

27. Lauber ME, Sarasin A, Lichtensteiger W. Transient sex differences of aromatase (CYP19) mRNA expression in the developing rat brain. Neuroendocrinology (1997) 66(3):173-80. doi: 10.1159/000127235

28. Acharya KD, Veney SL. Characterization of the G-protein-coupled membrane-bound estrogen receptor GPR30 in the zebra finch brain reveals a sex difference in gene and protein expression. Dev Neurobiol (2012) 72 (11):1433-46. doi: 10.1002/dneu.22004

29. Ikeda Y, Nagai A, Ikeda MA, Hayashi S. Sexually dimorphic and estrogendependent expression of estrogen receptor beta in the ventromedial hypothalamus during rat postnatal development. Endocrinology (2003) 144 (11):5098-104. doi: 10.1210/en.2003-0267

30. Yokosuka M, Okamura H, Hayashi S. Postnatal development and sex difference in neurons containing estrogen receptor-alpha immunoreactivity in the preoptic brain, the diencephalon, and the amygdala in the rat. J Comp Neurol (1997) 389(1):81-93. doi: 10.1002/(sici)1096-9861(19971208) 389:1<81::aid-cne6>3.0.co;2-a

31. Brock O, De Mees C, Bakker J. Hypothalamic expression of oestrogen receptor alpha and androgen receptor is sex-, age- and region-dependent in mice. $J$ Neuroendocrinol (2015) 27(4):264-76. doi: 10.1111/jne.12258

32. Kelly DA, Varnum MM, Krentzel AA, Krug S, Forger NG. Differential control of sex differences in estrogen receptor alpha in the bed nucleus of the stria terminalis and anteroventral periventricular nucleus. Endocrinology (2013) 154(10):3836-46. doi: 10.1210/en.2013-1239

33. Chakraborty TR, Rajendren G, Gore AC. Expression of estrogen receptor \{alpha\} in the anteroventral periventricular nucleus of hypogonadal mice. Exp Biol Med (2005) 230(1):49-56. doi: 10.1177/153537020523000106

34. Stanic D, Dubois S, Chua HK, Tonge B, Rinehart N, Horne MK, et al. Characterization of aromatase expression in the adult male and female mouse brain. I. Coexistence with oestrogen receptors alpha and beta, and androgen receptors. PloS One (2014) 9(3):e90451. doi: 10.1371/journal.pone.0090451

35. Zhang JQ, Cai WQ, Zhou DS, Su BY. Distribution and differences of estrogen receptor beta immunoreactivity in the brain of adult male and female rats. Brain Res (2002) 935(1-2):73-80. doi: 10.1016/s0006-8993(02)02460-5

36. Hazell GG, Yao ST, Roper JA, Prossnitz ER, O’Carroll AM, Lolait SJ. Localisation of GPR30, a novel G protein-coupled oestrogen receptor, suggests multiple functions in rodent brain and peripheral tissues. J Endocrinol (2009) 202(2):223-36. doi: 10.1677/JOE-09-0066

37. Khbouz B, de Bournonville C, Court L, Taziaux M, Corona R, Arnal JF, et al. Role for the membrane estrogen receptor alpha in the sexual differentiation of the brain. Eur J Neurosci (2020) 52(1):2627-45. doi: 10.1111/ejn.14646

38. Shi Y, Liu X, Zhu P, Li J, Sham KW, Cheng SH, et al. G-protein-coupled estrogen receptor 1 is involved in brain development during zebrafish (Danio rerio) embryogenesis. Biochem Biophys Res Commun (2013) 435(1):21-7. doi: 10.1016/j.bbrc.2013.03.130 
39. Tobiansky DJ, Will RG, Lominac KD, Turner JM, Hattori T, Krishnan K, et al. Estradiol in the Preoptic Area Regulates the Dopaminergic Response to Cocaine in the Nucleus Accumbens. Neuropsychopharmacology (2016) 41 (7):1897-906. doi: 10.1038/npp.2015.360

40. Simerly RB, Swanson LW, Handa RJ, Gorski RA. Influence of perinatal androgen on the sexually dimorphic distribution of tyrosine hydroxylaseimmunoreactive cells and fibers in the anteroventral periventricular nucleus of the rat. Neuroendocrinology (1985) 40(6):501-10. doi: 10.1159/000124122

41. Sumida H, Nishizuka M, Kano Y, Arai Y. Sex differences in the anteroventral periventricular nucleus of the preoptic area and in the related effects of androgen in prenatal rats. Neurosci Lett (1993) 151(1):41-4. doi: 10.1016/ 0304-3940(93)90040-R

42. Simerly RB, Zee MC, Pendleton JW, Lubahn DB, Korach KS. Estrogen receptor-dependent sexual differentiation of dopaminergic neurons in the preoptic region of the mouse. Proc Natl Acad Sci U S A (1997) 94(25):1407782. doi: $10.1073 /$ pnas.94.25.14077

43. Orikasa C, Kondo Y, Hayashi S, McEwen BS, Sakuma Y. Sexually dimorphic expression of estrogen receptor beta in the anteroventral periventricular nucleus of the rat preoptic area: implication in luteinizing hormone surge. Proc Natl Acad Sci U S A (2002) 99(5):3306-11. doi: 10.1073/pnas.052707299

44. Bodo C, Kudwa AE, Rissman EF. Both estrogen receptor-alpha and -beta are required for sexual differentiation of the anteroventral periventricular area in mice. Endocrinology (2006) 147(1):415-20. doi: 10.1210/en.2005-0834

45. Roque C, Mendes-Oliveira J. Baltazar G. G protein-coupled estrogen receptor activates cell type-specific signaling pathways in cortical cultures: relevance to the selective loss of astrocytes. J Neurochem (2019) 149(1):27-40. doi: 10.1111/ jnc. 14648

46. Sano K, Tsuda MC, Musatov S, Sakamoto T, Ogawa S. Differential effects of site-specific knockdown of estrogen receptor alpha in the medial amygdala, medial pre-optic area, and ventromedial nucleus of the hypothalamus on sexual and aggressive behavior of male mice. Eur J Neurosci (2013) 37 (8):1308-19. doi: 10.1111/ejn.12131

47. Dalpian F, Rasia-Filho AA, Calcagnotto ME. Sexual dimorphism, estrous cycle and laterality determine the intrinsic and synaptic properties of medial amygdala neurons in rat. J Cell Sci (2019) 132(9). doi: 10.1242/jcs.227793

48. Yoshida M, Suga S, Sakuma Y. Estrogen reduces the excitability of the female rat medial amygdala afferents from the medial preoptic area but not those from the lateral septum. Exp Brain Res (1994) 101(1):1-7. doi: 10.1007/ BF00243211

49. Tian Z, Wang Y, Zhang N, Guo YY, Feng B, Liu SB, et al. Estrogen receptor GPR30 exerts anxiolytic effects by maintaining the balance between GABAergic and glutamatergic transmission in the basolateral amygdala of ovariectomized mice after stress. Psychoneuroendocrinology (2013) 38 (10):2218-33. doi: 10.1016/j.psyneuen.2013.04.011

50. Lebow MA, Chen A. Overshadowed by the amygdala: the bed nucleus of the stria terminalis emerges as key to psychiatric disorders. Mol Psychiatry (2016) 21(4):450-63. doi: 10.1038/mp.2016.1

51. Hines M, Allen LS, Gorski RA. Sex differences in subregions of the medial nucleus of the amygdala and the bed nucleus of the stria terminalis of the rat. Brain Res (1992) 579(2):321-6. doi: 10.1016/0006-8993(92)90068-K

52. Jacobson CD, Csernus VJ, Shryne JE, Gorski RA. The influence of gonadectomy, androgen exposure, or a gonadal graft in the neonatal rat on the volume of the sexually dimorphic nucleus of the preoptic area. J Neurosci (1981) 1(10):1142-7. doi: 10.1523/JNEUROSCI.01-10-01142.1981

53. Rosie R, Wilson H, Fink G. Testosterone Induces an All-or-None, Exponential Increase in Arginine Vasopressin mRNA in the Bed Nucleus of Stria Terminalis of the Hypogonadal Mouse. Mol Cell Neurosci (1993) 4(1):1216. doi: 10.1006/mcne.1993.1014

54. Chung WC, Swaab DF, De Vries GJ. Apoptosis during sexual differentiation of the bed nucleus of the stria terminalis in the rat brain. J Neurobiol (2000) 43 (3):234-43. doi: 10.1002/(SICI) 1097-4695(20000605)43:3<234::AIDNEU2 $>3.0 . \mathrm{CO} ; 2-3$

55. Lu SF, McKenna SE, Cologer-Clifford A, Nau EA, Simon NG. Androgen receptor in mouse brain: sex differences and similarities in autoregulation. Endocrinology (1998) 139(4):1594-601. doi: 10.1210/endo.139.4.5863

56. Hisasue S, Seney ML, Immerman E, Forger NG. Control of cell number in the bed nucleus of the stria terminalis of mice: role of testosterone metabolites and estrogen receptor subtypes. J Sex Med (2010) 7(4 Pt 1):1401-9. doi: 10.1111/ j.1743-6109.2009.01669.x

57. Krentzel AA, Willett JA, Johnson AG, Meitzen J. Estrogen receptor alpha, Gprotein coupled estrogen receptor 1, and aromatase: Developmental, sex, and region-specific differences across the rat caudate-putamen, nucleus accumbens core and shell. J Comp Neurol (2020). doi: 10.1002/cne.24978

58. Naftolin F, Ryan KJ, Petro Z. Aromatization of androstenedione by the anterior hypothalamus of adult male and female rats. Endocrinology (1972) 90(1):295-8. doi: 10.1210/endo-90-1-295

59. Wehrenberg U, Prange-Kiel J, Rune GM. Steroidogenic factor-1 expression in marmoset and rat hippocampus: co-localization with StAR and aromatase. $J$ Neurochem (2001) 76(6):1879-86. doi: 10.1046/j.1471-4159.2001.00207.x

60. Pareto D, Biegon A, Alexoff D, Carter P, Shea C, Muench L, et al. In vivo imaging of brain aromatase in female baboons: [11C]vorozole kinetics and effect of the menstrual cycle. Mol Imaging (2013) 12(8):1-7. doi: 10.2310/ 7290.2013 .00068

61. Abdelgadir SE, Resko JA, Ojeda SR, Lephart ED, McPhaul MJ, Roselli CE. Androgens regulate aromatase cytochrome $\mathrm{P} 450$ messenger ribonucleic acid in rat brain. Endocrinology (1994) 135(1):395-401. doi: 10.1210/ endo.135.1.8013375

62. Wagner CK, Morrell JI. Neuroanatomical distribution of aromatase MRNA in the rat brain: indications of regional regulation. J Steroid Biochem Mol Biol (1997) 61(3-6):307-14. doi: 10.1016/S0960-0760(97)80028-3

63. Shay DA, Vieira-Potter VJ, Rosenfeld CS. Sexually Dimorphic Effects of Aromatase on Neurobehavioral Responses. Front Mol Neurosci (2018) 11:374:374. doi: 10.3389/fnmol.2018.00374

64. Roselli CE, Klosterman SA. Sexual differentiation of aromatase activity in the rat brain: effects of perinatal steroid exposure. Endocrinology (1998) 139 (7):3193-201. doi: 10.1210/endo.139.7.6101

65. Catalano S, Barone I, Giordano C, Rizza P, Qi H, Gu G, et al. Rapid estradiol/ ERalpha signaling enhances aromatase enzymatic activity in breast cancer cells. Mol Endocrinol (2009) 23(10):1634-45. doi: 10.1210/me.2009-0039

66. Catalano S, Giordano C, Panza S, Chemi F, Bonofiglio D, Lanzino M, et al. Tamoxifen through GPER upregulates aromatase expression: a novel mechanism sustaining tamoxifen-resistant breast cancer cell growth. Breast Cancer Res Treat (2014) 146(2):273-85. doi: 10.1007/s10549-014-3017-4

67. Wu MV, Manoli DS, Fraser EJ, Coats JK, Tollkuhn J, Honda S, et al. Estrogen masculinizes neural pathways and sex-specific behaviors. Cell (2009) 139 (1):61-72. doi: 10.1016/j.cell.2009.07.036

68. Tenkorang MA, Snyder B, Cunningham RL. Sex-related differences in oxidative stress and neurodegeneration. Steroids (2018) 133:21-7. doi: 10.1016/j.steroids.2017.12.010

69. Hull L, Mandy W, Petrides KV. Behavioural and cognitive sex/gender differences in autism spectrum condition and typically developing males and females. Autism (2017) 21(6):706-27. doi: 10.1177/1362361316669087

70. Rainville JR, Hodes GE. Inflaming sex differences in mood disorders. Neuropsychopharmacology (2019) 44(1):184-99. doi: 10.1038/s41386-0180124-7

71. Lebron-Milad K, Milad MR. Sex differences, gonadal hormones and the fear extinction network: implications for anxiety disorders. Biol Mood Anxiety Disord (2012) 2:3. doi: 10.1186/2045-5380-2-3

72. Walf AA, Frye CA. A review and update of mechanisms of estrogen in the hippocampus and amygdala for anxiety and depression behavior. Neuropsychopharmacology (2006) 31(6):1097-111. doi: 10.1038/sj.npp.1301067

73. Spiteri T, Musatov S, Ogawa S, Ribeiro A, Pfaff DW, Agmo A. The role of the estrogen receptor alpha in the medial amygdala and ventromedial nucleus of the hypothalamus in social recognition, anxiety and aggression. Behav Brain Res (2010) 210(2):211-20. doi: 10.1016/j.bbr.2010.02.033

74. Anchan D, Clark S, Pollard K, Vasudevan N. GPR30 activation decreases anxiety in the open field test but not in the elevated plus maze test in female mice. Brain Behav (2014) 4(1):51-9. doi: 10.1002/brb3.197

75. Hart D, Nilges M, Pollard K, Lynn T, Patsos O, Shiel C, et al. Activation of the Gprotein coupled receptor 30 (GPR30) has different effects on anxiety in male and female mice. Steroids (2014) 81:49-56. doi: 10.1016/j.steroids.2013.11.004

76. Kastenberger I, Lutsch C, Schwarzer C. Activation of the G-protein-coupled receptor GPR30 induces anxiogenic effects in mice, similar to oestradiol. Psychopharmacol (Berl) (2012) 221(3):527-35. doi: 10.1007/s00213-011-2599-3 
77. Petersen SL, Ottem EN, Carpenter CD. Direct and indirect regulation of gonadotropin-releasing hormone neurons by estradiol. Biol Reprod (2003) 69 (6):1771-8. doi: 10.1095/biolreprod.103.019745

78. Nikisch G, Mathe AA, Czernik A, Thiele J, Bohner J, Eap CB, et al. Long-term citalopram administration reduces responsiveness of HPA axis in patients with major depression: relationship with S-citalopram concentrations in plasma and cerebrospinal fluid (CSF) and clinical response. Psychopharmacol (Berl) (2005) 181(4):751-60. doi: 10.1007/s00213-0050034-3

79. McAllister CE, Mi Z, Mure M, Li Q, Muma NA. GPER1 stimulation alters posttranslational modification of RGSzl and induces desensitization of 5HT1A receptor signaling in the rat hypothalamus. Neuroendocrinology (2014) 100(2-3):228-39. doi: 10.1159/000369467

80. Findikli E, Kurutas EB, Camkurt MA, Karaaslan MF, Izci F, Findikli HA, et al. Increased Serum G Protein-coupled Estrogen Receptor 1 Levels and Its Diagnostic Value in Drug Naive Patients with Major Depressive Disorder.
Clin Psychopharmacol Neurosci (2017) 15(4):337-42. doi: 10.9758/ cpn.2017.15.4.337

81. Kastenberger I, Schwarzer C. GPER1 (GPR30) knockout mice display reduced anxiety and altered stress response in a sex and paradigm dependent manner. Horm Behav (2014) 66(4):628-36. doi: 10.1016/j.yhbeh.2014.09.001

Conflict of Interest: The authors declare that the research was conducted in the absence of any commercial or financial relationships that could be construed as a potential conflict of interest.

Copyright (c) 2020 Dovey and Vasudevan. This is an open-access article distributed under the terms of the Creative Commons Attribution License (CC BY). The use, distribution or reproduction in other forums is permitted, provided the original author(s) and the copyright owner(s) are credited and that the original publication in this journal is cited, in accordance with accepted academic practice. No use, distribution or reproduction is permitted which does not comply with these terms. 